\title{
ANALISIS KEKUATAN GESER SAMBUNGAN LAS TITIK MENGGUNAKAN MESIN LAS TITIK INVERTER
}

\author{
Abram Tangkemanda ${ }^{1}$, Muh. Iswar ${ }^{1}$, Tri AgusSusanto ${ }^{1}$, Akmal Kamaruddin ${ }^{1}$, Jummi Manda \\ Mangetan $^{2}$, Jono Tangdialla ${ }^{2}$
}

\begin{abstract}
Abstrak:, Analisis Kekuatan Geser Sambungan Mesin Las Titik Menggunakan Mesin Las Titik Inverter. Analisis kekuatan geser sambungan mesin las titik menggunakan mesin las titik inverter bertujuan untuk mengetahui pengaruh arus terhadap tegangan geser las titik inverter, pengaruh variasi sambungan terhadap tegangan geser las titik sistem inverter, pengaruh bahan Stainless AISI 304 dan St-42 terhadap tegangangeser las titik inverter. Uji mekanik bahan, pembuatan specimen pengujian (arus $80 \mathrm{~A}, 100 \mathrm{~A}$ ), analisis data regresi linier berganda, hasil dan pembahasan, kesimpulan. Hasil menunjukkan bahan Stainless Steel AISI 304 ketebalan 0,8 $\mathrm{mm}$ mempunyai hubungan negatif terhadap kenaikan tegangan geser, ketebalan $1 \mathrm{~mm}$ mempunyai hubungan posotif terhadap kenaikan tegangan geser, sedangkan bahan ST-42 ketebalan $0,8 \mathrm{~mm}$ dan $1 \mathrm{~mm}$ mempunyai hubungan negative terhadap kenaikan tegangan geser. Bahan Stainless Steel AISI 304 memiliki titik lebur yang rendah sehingga mampu menahan panas sedangkan bahan St-42 memiliki titik lebur yang tinggi sehingga pada ketebalan pelat tipis dan arusnya dinaikkan akan mengalami penurunan tegangan geser namun pada saat ketebalan bertambah dan arusnya dinaikkan bahan memiliki penetrasi yang lebih baik.
\end{abstract}

Kata Kunci : Analisis regresi linier berganda, Arus, Las titik inverter, Stainlees Steel AISI 304, St-42, Tegangan geser, Variasi sambungan.

\section{PENDAHULUAN}

Ada beberapa macam proses pengelasan salah satunya adalah las titik (spot welding) dimana dalam proses penyambungannya, logam dijepit dengan sepasang elektroda dan ketika arus dialirkan melalui logam maka aliran listrik akan memanaskan logam. Penggunaan arus cukup tinggi akan menghasilkan suhu yang cukup tinggi kemudian suhu tinggi ini akan mencapai suhu fusi logam, hal ini akan menyebabkan terjadinya sambungan las pada posisi jepitan. titik sambungan harus dilas penuh.

Kualitas dan kekuatan hasil sambungan las titik sangat penting dalam kelayakan dan keamanan alat transportasi dan alat rumah tangga sehingga perlu dilakukan penelitian lebih dalam. Penelitian tentang las titik telah dilakukan oleh Dewi dkk mahasiswa Jurusan Teknik Mesin Politeknik Negeri Ujung Pandang dengan menggunakan mesin las titik sistem transformator, Tetapi kelemahan yang masih ditemukan yaitu penggunaan daya listrik yang terlalu besar, maka dari itu kami akan melakukan penelitian menggunakan mesin las titik inverter untuk mengurangi daya listrik yang digunakana dengan bahan uji yang sama.

Maksud penelitian ini adalah untuk mengetahui kekuatan tegangan geser las titik inverter. Tujuan Penelitian ini adalah untuk mengetahui pengaruh arus,variasi sambungan dan pengaruh bahan terhadap tegangan geser las titik inverter.

Las (welding) adalah suatu cara untuk menyambung benda padat dengan mencairkannya melalui pemanasan. Las resistansi listrik adalah suatu cara pengelasan dimana permukaan plat yang disambung ditekankan satu sama lain diantara elektoroda-elektroda pembawa arus dan pada waktu yang sama arus listrik dialirkan sehingga kedua permukaan mengalami panas dan mencair. Las titik (spot welding) dilakukan dengan cara plat yang akan dilas dijepit pada tempat sambungan dengan menggunakan sepasang elektroda dari paduan tembaga. Setelah itu, dialiri arus listrik yang cukup tinggi untuk menghasilkan suhu yang tinggi dalam waktu yang singkat.

Sistem Inverter adalah Rangkaian elektronika daya yang digunakan untuk mengkonversikan tegangan searah (DC) ke suatu tegangan bolak-balik (AC). Sistem Transformator adalah suatu alat listrik yang dapat memindahkan dan mengubah energi listrik dari satu atau lebih rangkaian listrik ke

\footnotetext{
${ }^{1}$ Staf Pengajar D4 Jurusan Teknik Mesin Politeknik Negeri Ujung Pandang

${ }^{2}$ Alumni Program D4 Jurusan Teknik Mesin Politeknik Negeri Ujung Pandang
} 
37 Abram Tangkemanda, Muh. Iswar, Tri AgusSusanto, Akmal Kamaruddin, Jummi Manda Mangetan, Jono

Tangdialla. Analisis Kekuatan Geser Sambungan Las Titik Menggunakan Mesin Las Titik Inverter

rangkaian listrik yang lain, melalui suatu gandengan magnet dan berdasarkan prinsip induksielektromagnet. Uji Tarik adalah pengujian yang dilakukan untuk mengetahui sifat-sifat mekanik bahan teknik. Tegangan Geser berbeda dengan tegangan tarik dan tekan karena tegangan geser disebabkan oleh gaya yang bekerja sepanjang atau sejajar dengan luas penahan gaya sedangkan tegangan tarikdan tekan disebabkan oleh gaya yang tegak lurus terhadap luas bidang gaya. Analisis Regresi merupakan salah satu analisis yang bertujuan untuk mengetahui adanya pengaruh suatu variable terhadap variable lain untuk mendapatkan hubungan antara variable-variabel.

\section{METODOLOGI PENELITIAN}

Penelitian dilaksanakan di Bengkel Mekanik dan Laboratorium Mekanik Jurusan Teknik Mesin Politeknik Negeri Ujung Pandang.

\section{A. Pengumpulan Data Persiapan Bahan}

Sebelum melakukan proses pemotongan bahan, terlebih dahulu dilakukan pengujian mekanis terhadap bahan.

\section{Pemotongan Benda Kerja}

Memotong benda kerja yakni pelat Stainless AISI 304 dan pelat St-42dengan ukuran masing-masing ketebalan $220 \mathrm{~mm} \times 50 \mathrm{~mm}$. Jumlah potongan pelat yang dibutuhkan untuk spesimen uji sebanyak 280 potong.

\section{Pembuatan mal} sambungan.

Pembuatan mal digunakan untuk mempermudah penempatan titik sesuai dengan jenis

\section{Pengujian tarik}

Pengujian tarik dilakukan untuk mengetahui kekuatan tarik dari bahan uji yang sesuai dengan variasi arus dan jenis sambungannya.

\section{Metode Analisa Data}

Setelah melakukan uji tarik terhadap 280 sampel uji, maka diperoleh data tabel yang akan dianalisa secara statistik menggunakan model statistik analisis regresi linier berganda. Adapun bentuk pengolahan datanya menggunakan software SPSS.

\section{HASIL DAN PEMBAHASAN}

\section{A. Hasil Data Pengamatan}

Setelah melakukan uji tarik data tegangan geser diperoleh berdasarkan arus, variasi sambungan dan ketebalan yang telah ditentukan sebelumnya. Dimana, besar tegangan geser berbanding lurus dengan gaya dan berbanding terbalik dengan luas penampang.

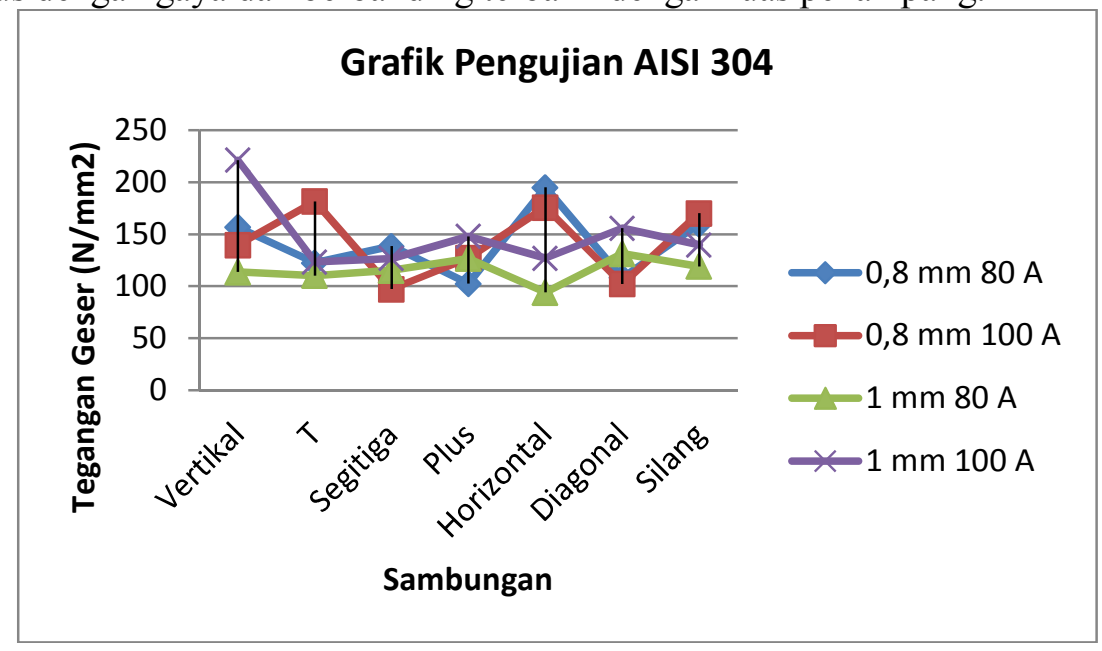




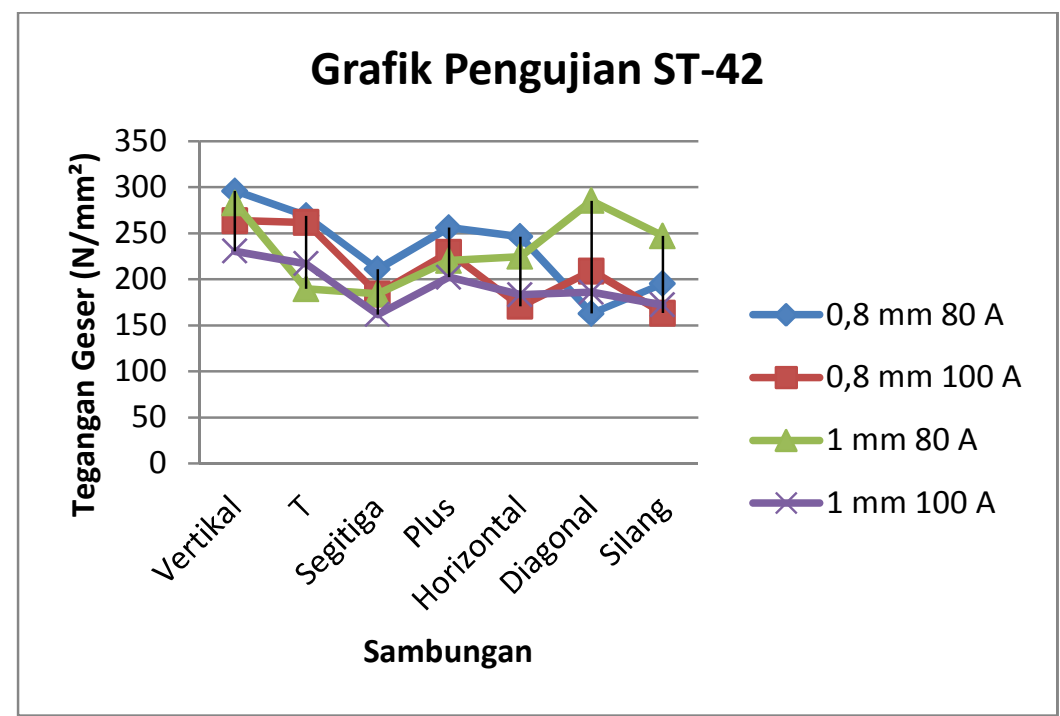

\section{B. Analisa pengaruh titik sambungan}

Untuk mengetahui jenis sambungan yang kuat tanpa memperhitungkan variabel pengelasannya adalah dengan mencari berapa banyak jumlah titik yang berpengaruh pada setiap sambungan, yaitu dengan cara member nilai setiap titik pada sambungan.

Sambungan Vertikal

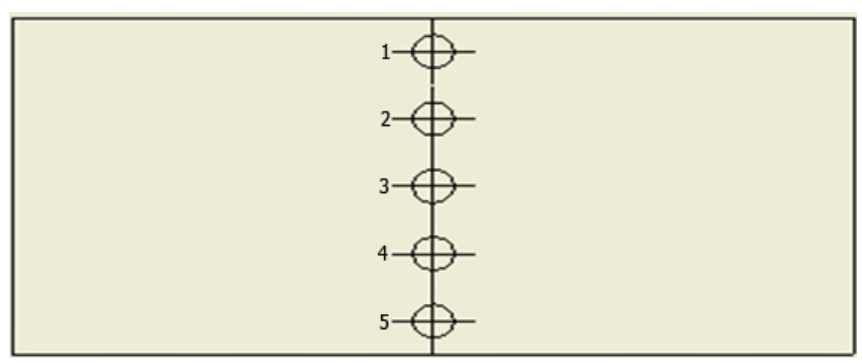

\section{Analisa data dan grafik}

\section{Stainless AISI 304}

Berdasarkan grafik didapatkan hasil bahwa sambungan Vertikal memiliki tegangan geser yang lebih tinggi, yang berarti sambungan tersebut memiliki kekuatan yang lebih baik dibanding sambungan lainnya.Hal ini disebabkan karena letak titik pada sambungan diagonal menempati bidang las dengan baik (arah horizontal dan vertikal dilalui titik sambungan).

St-42

Berdasarkan grafik didapatkan hasil bahwa sambunganvertikal memiliki tegangan geser yang lebih tinggi, yang berarti sambungan tersebut memiliki kekuatan yang lebih baik dibanding sambungan lainnya.

\section{Output analisa regresi}

Bahan Stainless Aisi 304

1. Sambungan Vertikal 
39 Abram Tangkemanda, Muh. Iswar, Tri AgusSusanto, Akmal Kamaruddin, Jummi Manda Mangetan, Jono Tangdialla. Analisis Kekuatan Geser Sambungan Las Titik Menggunakan Mesin Las Titik Inverter

Descriptive Statistics
\begin{tabular}{|l|r|r|r|}
\hline & \multicolumn{1}{|c|}{ Mean } & Std. Deviation & \multicolumn{1}{c|}{ N } \\
\hline Teg_Geser & 157.7970 & 68.95911 & 20 \\
Arus & 90.0000 & 10.25978 & 20 \\
Ketebalan & 9000 & .10260 & 20 \\
Penekanan & 7.0560 & .98514 & 20 \\
Lama_Penekanan & 6.4000 & 1.42902 & 20 \\
\hline
\end{tabular}

\begin{tabular}{|c|c|c|c|c|c|c|c|c|c|}
\hline \multirow[b]{3}{*}{ Model } & \multirow[b]{3}{*}{$\mathrm{R}$} & \multicolumn{7}{|c|}{ Model Summary' } & \\
\hline & & \multirow[b]{2}{*}{ R Square } & \multirow[b]{2}{*}{$\begin{array}{l}\text { Adjusted R } \\
\text { Square }\end{array}$} & \multirow[b]{2}{*}{$\begin{array}{l}\text { Std. Error of } \\
\text { the Estimate }\end{array}$} & \multicolumn{5}{|c|}{ Change Statistics } \\
\hline & & & & & $\begin{array}{c}\text { R Square } \\
\text { Change }\end{array}$ & F Change & df1 & d 2 & $\begin{array}{c}\text { Sig. F } \\
\text { Change }\end{array}$ \\
\hline 1 & $468^{2}$ & .219 & .011 & 68.59037 & .219 & 1.051 & 4 & 15 & .414 \\
\hline
\end{tabular}

a. Predictors: (Constant), Lama_Penekanan, Ketebalan, Arus, Penekanan

b. Dependent Variable: Teg.Geser

\begin{tabular}{|c|c|c|c|c|c|c|}
\hline \multicolumn{7}{|c|}{ ANOVA ${ }^{3}$} \\
\hline & & $\begin{array}{l}\text { Sum of } \\
\text { Squares }\end{array}$ & df & Mean Square & $\mathrm{F}$ & Sig. \\
\hline \multirow[t]{3}{*}{1} & Regression & 19782.242 & 4 & 4945.561 & 1.051 & $.414^{b}$ \\
\hline & Residual & 70569.582 & 15 & 4704.639 & & \\
\hline & Total & 90351.824 & 19 & & & \\
\hline
\end{tabular}

a. Dependent Variable: Teg.Geser

b. Predictors: (Constant), Lama_Penekanan, Ketebalan, Arus, Penekanan

\begin{tabular}{|c|c|c|c|c|c|c|c|c|c|}
\hline \multicolumn{10}{|c|}{ Coefficients $^{a}$} \\
\hline \multirow[b]{2}{*}{ Model } & & \multicolumn{2}{|c|}{ Unstandardized Coefficients } & \multirow{2}{*}{$\begin{array}{c}\text { Standardized } \\
\text { Coeficients } \\
\text { Beta }\end{array}$} & \multirow[b]{2}{*}{$\mathrm{t}$} & \multirow[b]{2}{*}{ Sig. } & \multicolumn{3}{|c|}{ Correlations } \\
\hline & & $\mathrm{B}$ & Std. Error & & & & Zero-order & Partial & Part \\
\hline 1 & (Constant) & -8.051 & 245.541 & &. .033 & .974 & & & \\
\hline & Arus & 2.121 & 1.538 & .316 & 1.379 & .188 & .337 & .335 & .315 \\
\hline & Ketebalan & 110.410 & 153.789 & .164 & .718 & 484 & .143 & .182 & .164 \\
\hline & Penekanan & -4.521 & 16.324 & .065 & -.277 & .786 & -.003 & .071 & -.063 \\
\hline & Lama_Penekanan & -14.450 & 11.312 & -.299 & -1.277 & .221 & -.297 & -.313 & -.292 \\
\hline
\end{tabular}

a. Dependent Variable: Teg.Geser

Dari hasil output regresi tersebut, maka diperoleh persamaan regresi dari sambungan horizontal sebagai berikut :

$$
\begin{aligned}
& Y=a+b_{1} \cdot X_{1}+b_{2} \cdot X_{2}+b_{3} \cdot X_{3}+b_{4} \cdot X_{4} \\
& Y=\mathbf{- 8 , 0 5 1}+\mathbf{2}, \mathbf{1 2 1} X_{1}+\mathbf{1 1 0}, \mathbf{4 1 0} \mathbf{X}_{\mathbf{2}}-\mathbf{4 , 5 2 1} \mathbf{X}_{\mathbf{3}}-\mathbf{1 4 , 4 5 0} \mathbf{X}_{4}
\end{aligned}
$$

\section{Bahan St-42}

1. Sambungan Vertikal 


\begin{tabular}{|c|c|c|c|}
\hline \multicolumn{4}{|c|}{ Descriptme Statistics } \\
\hline & Mean & Std. Dewation & $\mathbb{N}$ \\
\hline Teg.Geser & 268.9300 & 113.04794 & 20 \\
\hline Arus & 90.0000 & 10.25978 & 20 \\
\hline Ketebalan & .9000 & .10260 & 20 \\
\hline Penekanan & 7.0560 & .98514 & 20 \\
\hline Lama.Tekan & 6.2000 & .89443 & 20 \\
\hline
\end{tabular}

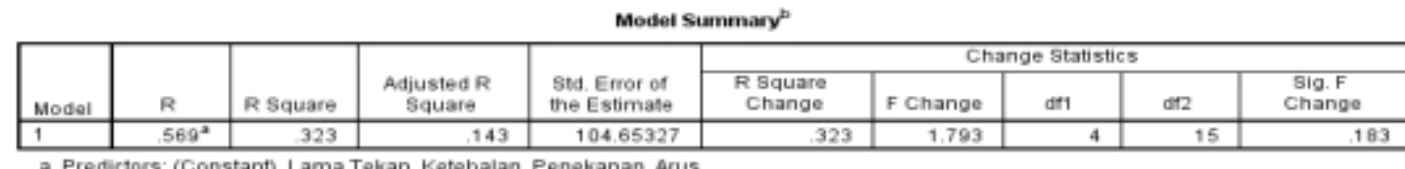

a. Predictors: (Constant), Lama.Takan, Ketebalan, Penakanan, Arus

b. Dependent Variable: Teg.Geser

\begin{tabular}{|c|c|c|c|c|c|c|}
\hline \multicolumn{7}{|c|}{ ANOVA" } \\
\hline Model & & $\begin{array}{l}\text { Sum of } \\
\text { squares }\end{array}$ & of & Mean Square & $\mathrm{F}$ & sig. \\
\hline \multirow[t]{3}{*}{1} & Regression & 78532.275 & 4 & 19633.069 & 1.793 & $.183^{6}$ \\
\hline & Residual & 164284.619 & 15 & 10952.308 & & \\
\hline & Total & 242816.894 & 19 & & & \\
\hline
\end{tabular}

a. Dependent Variable: Teg Geser

b. Predictors: (Constant), Lama.Tekan, Ketebalan, Penekanan, Arus

Coefficients $^{\mathrm{a}}$

\begin{tabular}{|c|c|c|c|c|c|c|c|c|c|}
\hline \multirow[b]{2}{*}{ Mod } & & \multicolumn{2}{|c|}{ Unstandardized Coefficients } & \multirow{2}{*}{$\begin{array}{c}\begin{array}{c}\text { Standardized } \\
\text { Coefficients }\end{array} \\
\text { Beta }\end{array}$} & \multirow[b]{2}{*}{$t$} & \multirow[b]{2}{*}{ Sig. } & \multicolumn{3}{|c|}{ Correlations } \\
\hline & & $\mathrm{B}$ & Std. Error & & & & Zero-order & Partial & Part \\
\hline \multirow[t]{5}{*}{1} & (Constant) & 756.231 & 411.462 & & 1.838 & .086 & & & \\
\hline & Arus & -1.289 & 2.498 & -.117 & -.516 & .613 & -.186 & -.132 & -.110 \\
\hline & Ketebalan & -109.240 & 234.012 & -.099 & -.467 & .647 & -.099 & -.120 & -.099 \\
\hline & Penekanan & -61.072 & 24.871 & -.532 & -2.456 & .027 & -.494 & -.535 & -.522 \\
\hline & Lama.Tekan & 25.476 & 29.176 & .202 & .873 & .396 & .142 & .220 & .185 \\
\hline
\end{tabular}

a. Dependent Variable: Teg.Geser

Dari hasil output regresi tersebut, maka diperoleh persamaan regresi dari sambungan horizontal sebagai berikut :

$$
\begin{aligned}
& Y=a+b_{1} \cdot X_{1}+b_{2} \cdot X_{2}+b_{3} X_{3}+b_{4} \cdot X_{4} \\
& Y=756,231-1,289 X_{1}-109,240 X_{2}-61,072 X_{3}+25,476 X_{4}
\end{aligned}
$$

\section{E. Analisa grafik hasil regresi}

Analisis grafik digunakan untuk melihat secara jelas perbandingan uji signifikansi regresi dan uji model regresi untuk setiap sambungan yang diteliti

\begin{tabular}{|c|c|c|c|c|}
\hline \multirow{2}{*}{ Sambungan } & \multicolumn{2}{|c|}{ Stainless AISI 304 } & \multicolumn{2}{|c|}{ St-42 } \\
\cline { 2 - 5 } & $\mathrm{F}$ & $\mathrm{R}$ & $\mathrm{F}$ & $\mathrm{R}$ \\
\hline Vertikal & 1.051 & 0.468 & 1.793 & 0.569 \\
\hline $\mathrm{T}$ & 1.954 & 0.585 & 2.073 & 0.597 \\
\hline Segitiga & 0.388 & 0.306 & 2.040 & 0.594 \\
\hline Plus & 1.419 & 0.524 & 0.584 & 0.367 \\
\hline Horizontal & 1.150 & 0.484 & 1.678 & 0.556 \\
\hline Diagonal & 1.719 & 0.561 & 2.230 & 0.611 \\
\hline Silang & 3.288 & 0.684 & 2.906 & 0.661 \\
\hline
\end{tabular}

\section{F. Perbandingan Data Mesin Las Titik Transformator Dengan Mesin Las Titik Inverter}


41 Abram Tangkemanda, Muh. Iswar, Tri AgusSusanto, Akmal Kamaruddin, Jummi Manda Mangetan, Jono

Tangdialla. Analisis Kekuatan Geser Sambungan Las Titik Menggunakan Mesin Las Titik Inverter

Setelah melakukan penelitian tentang tegangan geser pada mesin las titik inverter dimana jenis sambungan, arus, dan ketebalan plat sangat berpengaruh pada hasil pengelasan.Untuk membandingkan kekuatan pengelasan mesin las titik inverter dan mesin las titik transformator maka data mesin las titik transformator dilampirkan dari skripsi Dewi dkk, mahasiswa teknik mesin 2014. Skripsi ini mempunyai data yang dapat dibandingkan dengan data mesin las titik inverter, perbandingan yang dapat dilihat yaitu pada pengaruh sambungan dimana pada penelitian ini mempunyai 7 jenis sambungan, dan perbandingan jenis bahan yaitu Stainless Steell AISI 304 dan St-42 dengan ketebalan $0,8 \mathrm{~mm}$ dan $1 \mathrm{~mm}$.

Berdasarkan hasil perbandingan data antara mesin las titik inverter dengan mesin las titik transformator maka dari ketujuh sambungan mesin las titik transformator memiliki kekuatan sambungan yang lebih baik dibandingkan dengan mesin las titik inverter.

\section{KESIMPULAN DAN SARAN}

A. KESIMPULAN

1. Pada bahan stainless AISI 304 dengan ketebalan $0,8 \mathrm{~mm}$ mempunyai hubungan negatif terhadap kenaikan nilai tegangan geser, kecuali pada sambungan plus dan T mempunyai hubungan positif terhadap kenaikan tegangan geser. Pada ketebalan $1 \mathrm{~mm}$ mempunyai hubungan positif terhadap kenaikan tegangan geser. Hal ini dapat dibuktikan pada gambar 4.2 tentang grafik pengaruh arus terhadap tegangan geser bahan AISI 304. Sedangkan untuk bahan ST-42 dengan ketebalan 0,8 $\mathrm{mm}$ dan $1 \mathrm{~mm}$ mempunyai hubungan negatif terhadap kenaikan nilai tegangan geser. hal ini dibuktikan pada gambar 4.5 yang menampilkan Grafik pengaruh arus terhadap tegangan geser bahan ST-42.

2. Berdasarkan gambar 4.3 tentang grafik pengaruh variasi sambungan terhadap tegangan geser bahan stainless AISI 3014, jenis sambungan yang memiliki tegangan geser yang lebih besar yaitu sambungan horizontal. Sedangkan pada bahan ST-42 sambungan yang memiliki pengaruh tegangan geser yang lebih besar yaitu sambungan vertikal. Hal ini dibuktikan pada gambar 4.6 tentang grafik pengaruh sambungan terhadap tegangan geser bahan ST-42.

3. Untuk bahan pelat AISI 304 meskipun arus dinaikkan menjadi 100 Ampere, panas dari proses pengelasan mampu ditahan oleh pelat karena bahan ini memiliki titik lebur yang rendah dibanding bahan pelat St-42 yang memiliki titik lebur lebih tinggi sehingga pada saat ketebalan pelat tipis dan arusnya dinaikkan maka akan terjadi penurunan tegangan geser namun pada saat ketebalan bertambah dan arusnya dinaikkan bahanakan memiliki penetrasi yang lebih baik.

\section{B. SARAN}

Pada penelitian selanjutnya disarankan untuk lebih memperhatikan variabel pengelasan lainnya yang belum diteliti, misalnya waktu tekan.

\section{DAFTAR PUSTAKA}

Dewi, dkk.2014. Pengaruh Arus dan Variasi Sambungan Las Titik Terhadap Tegangan Geser Bahan Pelat Stainless Steel AISI 304 dan Pelat Baja St-42.Jurusan Teknik Mesin Politeknik Negeri Ujung Pandang.Makassar: Politeknik Negeri Ujung Pandang.

Kenyon, W., Dines, Ginting. 1985. Dasar-Dasar Peengelasan, Jakarta : Erlangga.

Suratman, Maman. 2001. Teknik Pengelasan Asitilen, Brazing dan Las Busur Listrik. Bandung: Pustaka Grafika.

Widharto, Sri. 1987. Petunjuk Kerja Las, Jakarta: Pradnya Paramita.

Wiryososumarto, Harsono., Toshe Okumura. 1996 Teknologi Pengelasan Logam. Pradnya Paramita. Zainuri, Ach.,Muhib. 2008. Kekuatan Bahan, Yogyakarta : Andi. 